\title{
Gênero e Território na Geografia Portuguesa: Entrevista com Margarida Queirós
}

\author{
Joseli Maria Silva \\ (Universidade Estadual de Ponta Grossa, Brasil) \\ Paulo Jorge Vieira \\ (Centro de Estudos Geográficos, Instituto de \\ Geografia e Ordenamento do Território, \\ Universidade de Lisboa, Portugal)
}

O Brasil registrou um trágico recorde em 2011. Mais de mil e quinhentas pessoas morreram ou desapareceram em enchentes e deslizamentos de terras no país, conforme afirmação do ministro da Ciência e Tecnologia, Aloizio Mercadante. Esses episódios têm despertado interesse da sociedade brasileira em torno da necessidade de redução da vulnerabilidade de grupos sociais aos riscos de desastres ambientais. A vulnerabilidade não é homogênea para toda a sociedade e tem sido alvo de discussões científicas, sendo que gênero, além da renda e da raça, são elementos a serem considerados. É nesse contexto social e político que temos a honra de entrevistar a geógrafa portuguesa Margarida Maria de Araújo

Abreu Vilar de Queirós do Vale, cuja abordagem da relação entre gênero e ambiente pode contribuir para o debate contemporâneo brasileiro.

Margarida Queirós é Professora do Instituto de Geografia e Ordenamento do Território e investigadora do Centro de Estudos Geográficos da Universidade de Lisboa. Sua atuação se dá nos núcleos de Modelação, Ordenamento e Planejamento Territorial (MOPT) e de Avaliação e Gestão de Perigos e Risco Ambiental (RISKam). Sua atuação na área de planejamento, ambiente e de riscos naturais resultou em uma sólida atuação em políticas governamentais como desenvolveu um importante caminho como pesquisadora e docente do ensino superior.

Entrevistar Margarida Queirós a fim de compartilhar o conhecimento dessa brilhante geógrafa com os leitores da Revista Latino-americana de Geografia e Gênero é uma importante tarefa que temos a honra de realizar.

Joseli Maria Silva e Paulo Jorge Vieira: Sua atuação com a relação entre ambiente, espaço e gênero tem obtido caminhos abertos para o diálogo com outras áreas da Geografia portuguesa?
Margarida Queirós: Sim, pelo menos para mim. Esse relacionamento ocorre através do planeamento e o ordenamento do território. Quando orientei a minha pesquisa para os temas do ambiente nos anos 1990 e depois para o ordenamento do território, no início da década de 2000, o meu entendimento sobre as análises de gênero alinhava pelo discurso geográfico hegemónico onde predomina uma certa neutralidade sobre os temas feministas. Só mais recentemente, quando a Comissão para a Cidadania e a Igualdade de Género (CIG) desafiou o Centro de Estudos Geográficos (CEG) para elaborar um estudo sobre 'género, ambiente e território', porque pretendia implementar uma política de mainstreaming de género em diversos domínios de política, entre os quais o 'ambiente e o território' é que me consciencializei como estava alinhada à ortodoxia das pesquisas, que ignoram as relações género-espaço.

À exceção da pesquisa inovadora que a colega geógrafa, Isabel André, desenvolveu no início dos anos 1990, reconheço que hoje, a geografia portuguesa não apresenta uma linha de pesquisa alicerçada sobre a categoria 'gênero' e que o trabalho que tenho desenvolvido com o apoio de alunos, colegas do MOPT (Modelação, Ordenamento e Planeamento Territorial, do CEG) e da CIG me estimula a continuar; inclusive alguns jovens que estão agora a iniciar a sua pesquisa comigo se começam a interessar por ele. Creio que estou hoje em condições de dizer que o 'gênero' é uma categoria analítica que timidamente começa a ter visibilidade na geografia portuguesa, por via da associação ao ordenamento do território e ao urbanismo. A confirmá-lo, a linha de pesquisa que estou começando a desenvolver encaminha-se para o estudo da construção social e cultural das relações de gênero e a sua expressão com a envolvente urbana algo que já tem uns 20 anos na investigação geográfica feminista anglo-saxónica e espanhola! 
JMS e PJV: Sua história profissional evidencia um trânsito entre a pesquisa acadêmica e a prática em projetos governamentais, como pode ser observado no 'Estudo de Diagnóstico e Criação de Indicadores de Género na área do Ambiente e Território', na elaboração de um 'Guia de Mainstreaming de Género' e, ainda no 'Estudo sobre Políticas e Medidas de Igualdade e Combate à Discriminação nas Autarquias Locais' que resultou no 'Guia para o combate à discriminação nos Municípios Planear para todos e todas, planear a diversidade'. Essa atuação acadêmica e prática é uma busca pessoal? Qual é sua opinião sobre essa vinculação entre conhecimento científico e ação social e política?

MQ: A este propósito tenho de fazer uma referência ao Professor Jorge Gaspar, cuja influência na minha vida profissional foi fundamental para que hoje possa dar uma resposta lúcida a esta pergunta. Jorge Gaspar foi uma influência incontornável no meu percurso académico: se, por um lado, me conduziu ao ensino universitário em geografia, através da disciplina de Geografia Humana, de onde nunca mais saí até à data, por outro, foi meu orientador de tese de doutoramento. A sua indiscutível autoridade na ciência geográfica portuguesa, bem como a disciplina e o rigor que sempre colocou nos trabalhos onde teve responsabilidades, foram (e serão), para mim, uma inspiração.

Terminada e defendida a tese, desafiou-me a coadjuvar a coordenação de alguns dos mais importantes trabalhos que fiz, o Programa Nacional da Política de Ordenamento do Território (PNPOT), que viria a ser um Decreto-lei em 2007. Foi a tarefa mais dura e estressante que desempenhei, mas também a que mais me ensinou e preparou para o que viria a seguir. A autonomia e a confiança para formular propostas, e o rigor e a exigência que colocou na minha prestação para este desafio maior - e para outros que entretanto me fez -, foram essenciais na minha preparação como académica atenta às exigências da sociedade civil. Foi esta uma das maiores lições para a minha formação: entendi que a geografia aplicada pode servir o interesse público. Entendo ser este o meu lugar na geografia e na sociedade.

Jorge Gaspar, impeliu-me para o mundo do planeamento e com ele pude entender o valor social da geografia. Daqui nasceriam para mim as primeiras ligações sérias da atividade académica com a sociedade civil. Foi neste espaço de contaminação cruzada, criteriosamente atenta às solicitações da sociedade, que me fui situando com os estudos em que a seguir colaborei, quer para a Comissão de
Coordenação de Lisboa e Vale do Tejo, a Autoridade Nacional de Proteção Civil ou a Comissão para a Cidadania e a Igualdade de Género. .

JMS e PJV: Suas obras, em geral voltadas para espaço e meio ambiente tem incorporado o gênero como importante elemento de suas análises. Como e porque o gênero passou a compor seus trabalhos?

MQ: Reconheço que o interesse pela categoria 'gênero' na investigação geográfica como eixo fundamental da diferenciação sociocultural não nasceu em mim como uma necessidade. Foi um desafio que veio 'de fora'. E foi muito curioso como tudo aconteceu: primeiro, em 2008, o Prof. Jorge Gaspar perguntou-me se eu estaria interessada em trabalhar o tema porque o CEG tinha recebido um convite da CIG para apresentar uma proposta de um estudo, e achava que eu estaria à altura da tarefa. Assim o fiz porque sou incapaz de fugir a um desafio. Depois, no ano seguinte, usufrui da minha licença sabática no Departamento de Geografia da Universidade Autónoma de Barcelona (UAB), onde está alojado o grupo de referência em 'geografia do gênero' na Península Ibérica, liderado pela incontornável Prof. Maria Dolors Garcia-Ramón. Se bem que o objetivo da minha estadia na UAB não se relacionasse com as perspectivas feministas, mas sim com o estudo de conflitos nos processos de planeamento estratégico, na cidade de Barcelona, este grupo, muito dinâmico e de elevada qualidade científica, desenvolvia tertúlias fantásticas para as quais me convidava frequentemente. Foi assim que acabei conhecendo referências internacionais na pesquisa geográfica ligadas aos estudos feministas, como Janice Monk, Lourdes Benería ou Doreen Massey e me comecei, de facto, a aperceber que havia matéria digna de ser investigada. Assim, de regresso à Universidade de Lisboa, recebo renovado convite, agora direto, para fazer outro estudo para a CIG que havia iniciado um processo de 'territorialização' da suas políticas para a igualdade e combate à discriminação. $\mathrm{E}$ foi assim que tudo começou.

Depois, a atividade em planeamento - que não havia ficado apenas pelo PNPOT -, sedimentada pelas pesquisas entretanto desenvolvidas para a proteção civil (ANPC) sobre as vulnerabilidades humanas ao risco (no âmbito do Estudo do Risco Sísmico e de Tsunamis no Algarve) e para a Comissão de Coordenação e Desenvolvimento Regional de Lisboa e Vale do Tejo (CCDR-LVT), sobre o Plano Regional de Ordenamento do Território do Oeste e Vale do Tejo, veio claramente demonstrar-me que as estruturas territoriais, sobretudo no que respeita ao território 
urbano, intensificam as desigualdades. Mais ainda: que as comunidades (no sentido relacional) estão dependentes dos contextos e são definidas por relações de poder, logo, os seus limites são estabelecidos por mecanismos de inclusão/exclusão daí resultando a discriminação de certos grupos. Ao dar-me conta desta evidência comecei a 'ver' a desigual distribuição de bens, serviços e recursos no espaço, influenciando as oportunidades dos utilizadores/residentes e a forma como uns se posicionam relativamente aos outros. David Harvey e Ed. Soja são geógrafos com importantes referências nesta reflexão. Mas Clara Greed foi visivelmente uma influência ímpar, já que me permitiu ver que é possível o planeamento ser sensível aos problemas de gênero e que as mulheres devem ter um papel central nesta atividade. Esta foi, aliás, a abordagem da minha equipa para chegar ao 'Guia para o combate à discriminação nos Municípios' em que questões como gênero, idade, sexualidade, etnicidade e deficiência são importantes para pensar 'a quem' se dirige o planeamento, para e com quem fazemos a cidade.

\section{JMS e PJV: As tendências teóricas e metodológicas das Geografias Feministas possuem alguma influência em seu trabalho na área de planejamento regional e local? De que forma?}

MQ: Em termos metodológicos, não há muita novidade, até porque estamos a começar a dar os primeiros passos nas abordagens das 'geografias feministas', por isso, creio que recorremos aos métodos tradicionais em geografia, combinando metodologias qualitativas e quantitativas. No que respeita ao posicionamento teórico, preocupo-me sobretudo com a ideia que exponho de seguida.

Aceitando uma concepção do feminismo como um movimento político e um campo teórico de análise, e que se manifesta por uma diversidade de abordagens, as chamadas 'geografias feministas', então eu sou influenciada por elas. Se quero mudar as relações entre o sexo, o gênero e o poder, tenho de manter um compromisso político. Não é tarefa simples porque este discurso teórico abala os fundamentos das instituições sociais nas suas aborrecidas e convencionais divisões de gênero. E procuro que não se entenda a minha mensagem como aquela que desmascara a oposição homem/mulher porque essa postura remete para o 'gênero' como um atributo do feminino. E a crer pelas sessões públicas de divulgação do trabalho que o grupo do CEG faz pelo país, essa é a via errada. Então, procuro que o nosso contributo consista em aclarar a relações entre as divisões de género e as espaciais, e mostrar os problemas ocultos por detrás da aparente neutralidade dos lugares. O que me preocupa neste momento como área de pesquisa, é desvendar o modo distinto como mulheres e homens, ao longo dos seus ciclos de vida, e portanto com diferentes necessidades e aspirações, utilizam o espaço público e essas diferenças são - em parte - construídas e, não raras vezes, aprofundadas pelos planeadores e processos de planeamento. E deste modo, torna-se imprescindível repensar o conceito de espaço público introduzindo a ideia que a sua configuração ou desenho, bem como as suas ofertas (equipamentos, bens e serviços) consentem o acesso de uns e dificultam o de outros. No papel social, que acredito a geografia ter, este é agora o meu foco: mostrar, através de evidências, que o território não é neutro e que a equidade territorial deve ser um objetivo a não perder de vista, sobretudo por parte de quem tem responsabilidades no ordenamento do território. Os recursos do território devem ser equitativamente acessíveis, só assim o princípio da igualdade social se aplica.

JMS e PJV: Em seu projeto 'Estudo sobre Políticas e Medidas de Igualdade e Combate à Discriminação nas Autarquias Locais' há uma atenção para várias formas de discriminação. Como analisa a importância recente na investigação geográfica que considera múltiplas discriminações e interseccionalidade?

MQ: O estudo dirigido para as autarquias locais culminou com a elaboração de uma 'guia de planeamento inclusivo' que tem por objetivo levar as Câmaras Municipais (Prefeituras) a elaborar planos municipais para a igualdade. Quando a CIG nos procurou para elaborar este estudo, buscava a produção de um documento que estimulasse e orientasse a atuação das Prefeituras no domínio da igualdade e da não-discriminação, daí surgir a figura do 'Plano Municipal para a Igualdade de Género' promovido pela CIG, um instrumento de apoio à atuação das(os) Conselheiras(os) para a Igualdade. Neste contexto, é a própria instituição que nos convoca para abordar as múltiplas discriminações (idade, gênero, orientação sexual, origem étnica, deficiência, religião ou crença), que é atualmente uma das áreas estratégicas de atuação da União Europeia.

É assim que se explica o desafio da abordagem que se orienta para a definição de políticas, medidas e ações em diversos domínios da discriminação: no emprego, na vida familiar, no desporto e no lazer, na saúde, na educação, na justiça, etc., de acordo com as categorias analíticas (idade, género, orientação sexual, origem étnica, deficiência, religião ou crença)

Joseli Maria Silva e Paulo J orge Vieira 
assegurando formalmente um idêntico nível de ações nos Estados-membros contra a discriminação.

Neste particular aspecto a inovação da abordagem cruzada não é da nossa iniciativa, mas o que daí resulta já se poderá aproximar. Quero com isto dizer que o que procuramos fazer foi colocar a questão deste modo: as medidas de igualdade e anti-discriminação dirigem-se ao 'gênero' enquanto compromisso político e essa visão engloba todas as outras, ou seja, ao logo da nossa vida somos mulheres e homens, jovens, adultos e idosos, com problemas de saúde, de mobilidade, deficiência, professando diferentes credos ou opções sexuais, etc. O 'ciclo de vida' e as suas diferentes fases é a chave para conseguir trabalhar estas aparentes categorias. Assim, a nossa abordagem parte dos seguintes pressupostos:

- a discriminação decorre da nacionalidade, origens étnicas, religiosas, ou orientação sexual, da deficiência, género e idade, dentro e fora do mercado de trabalho ou na família;

- a discriminação não ocorre apenas no emprego mas também no acesso a bens e serviços, como os transportes, habitação, saúde, educação, informação, crédito e seguros, ou mesmo no uso do espaço público.

- a discriminação ocorre no quotidiano, sempre que nos deparamos com soluções permanentes, coletivas e homogêneas planeadas no passado para responder às procuras da habitação, do comércio, dos transportes e dos lazeres que já não respondem perante o processo de individualização e de diversificação que caracteriza a sociedade atual.

Termino afirmando que, em resposta às discriminações referidas, (i) as ofertas públicas 'personalizadas' alargam as possibilidades de escolha e adaptam-se a uma variedade de situações, minorando desigualdades; (ii) é indispensável aprofundar o conhecimento das necessidades diferenciadas da população, segundo o sexo, a idade, a etnia, a orientação sexual e a deficiência, bem como criticar os desenhos generalistas e hegemónicos de um planeamento homogeneizante e uma sociedade que o aceita sem objeções.

Este conhecimento serve políticas adequadas para um desenho e distribuição mais equitativa de bens e serviços e instrumentos que permitam traduzir as políticas em ações inclusivas. Serve ainda para, no campo teórico das 'geografias feministas', aprofundar conceitos e perspectivas.

Termino com um desejo: que se reserve um lugar para o aprofundamento da investigação geográfica portuguesa a partir do conhecimento da espacialização da vida quotidiana e das relações de poder associadas, e que deste saber se produzam melhores lugares, resultantes de políticas e de processos de planeamento sensíveis às questões de gênero.

À Joseli e ao Paulo, agradeço muito estas perguntas que me fizeram refletir sobre o que faço e me desafiam a continuar um percurso recentemente iniciado.

\section{Referências}

QUEIRÓS, Margarida. "Planear a Sustentabilidade e Diversidade dos Territórios. Uma Reflexão a Partir do Guia para o Combate à Discriminação nos Municípios”. Revista Ex-Aequo, n²5, 2011.

QUEIRÓS, Margarida (ed.). Políticas de Igualdade nas Autarquias Locais. Lisboa: Centro de Estudos Geográficos, Universidade de Lisboa, 2011.

QUEIRÓS, Margarida. "Rumo à construção de uma agenda de investigação 'Género Ambiente' em Portugal". Revista Latino-americana de Geografia e Gênero. v.1, n1, p. 106-115, 2010.

QUEIRÓS, Margarida, MARQUES DA COSTA, N. PALMA, P. CAETANO, G, VIEIRA, P. J. Guia para o combate à discriminação nos Municípios. Planear para todos e todas, planear a diversidade Estudo sobre Políticas e Medidas de Igualdade e Combate à Discriminação nas Autarquias Locais. Projecto PROGRESS 2007-2013 Abordar as Discriminações Localmente para atingir a Igualdade a Nível Global. Lisboa: Comissão para a Cidadania e a Igualdade de Género / Instituto de Geografia e Ordenamento do Território da Universidade de Lisboa e Centro de Estudos Geográficos da Universidade de Lisboa, 2010, $103 \mathrm{p}$.

QUEIRÓS, Margarida, MARQUES DA COSTA, N. PALMA, P. CAETANO, G, VIEIRA, P. J. Estudo sobre Políticas e Medidas de Igualdade e Combate à Discriminação nas Autarquias Locais. Relatório Julho 2010. Projecto PROGRESS 2007-2013 Abordar as Discriminações Localmente para atingir a Igualdade a Nível Global. Lisboa: Comissão para a Cidadania e a Igualdade de Género / Instituto de Geografia e Ordenamento do Território da Universidade de Lisboa e Centro de Estudos Geográficos da Universidade de Lisboa, 2010, 67p.

GASPAR, J, QUEIRÓS, Margarida. (coord.), et al. Estudo de Diagnóstico e Criação de Indicadores de 
Gênero e Território na Geografia Portuguesa: Entrevista com Margarida Queirós

Género na Área do Território e Ambiente. Lisboa: Centro de Estudos Geográficos da Universidade de Lisboa/Faculdade de Letras da Universidade de Lisboa \& Comissão para a Cidadania e a Igualdade de Género, 2009.

GASPAR, J, QUEIRÓS, Margarida. (coord.), et al. Guia para o Mainstreaming de Género na Área do Território e Ambiente. Lisboa: Centro de Estudos Geográficos da Universidade de Lisboa/Faculdade de Letras da Universidade de Lisboa \& Comissão para a Cidadania e a Igualdade de Género, 2009. 